\title{
Energy economics: The case of emission markets
}

\author{
Georg Erdmann(*) \\ Energy Systems of TU Berlin - Einsteinufer 25, D-10587, Berlin, Germany \\ Aaron Praktiknjo(**) \\ E.ONN Energy Research Center, RWTH Aachen - Aachen, Germany
}

Summary. - The typical proposition of economists to solve the greenhouse gas problem (GHG) is that governments should put a price on these emissions. As human behavior can be influenced by prices, high prices on GHG emissions would imply lowering these emissions. One reaction would be to substitute the burning fossil fuels by non-fossil fuels such as wind, photovoltaics, geothermal and hydropower, eventually nuclear. The second would be innovations towards satisfying human needs by less energy. The third would be to avoid the GHG emissions by carbon capture and storage technologies. However, putting a price on GHG emissions requires political actions. Politicians have basically two alternatives. One would be to introduce a fiscal tax on GHG emissions, whereby the tax rate represents the price of the emission. The other is to implement a cap-and-trade system for GHG emissions, which requires that companies have to cover each emission unit by an emission right issued by the government. When these emission rights are traded, the market price of these rights represents the emission price. Common to both systems are sanctions on companies that do not comply. Today both systems have been implemented somewhere in the world to control GHG emissions so that their comparable benefits and disadvantages can be studied in reality.

\section{1. - Introduction}

The GHG effect is the consequence of certain gases in the atmosphere, in particular water vapor, carbon dioxide $\left(\mathrm{CO}_{2}\right)$, methane $\left(\mathrm{CH}_{4}\right)$, and nitrous oxide $\left(\mathrm{N}_{2} \mathrm{O}\right)$. According to climatologists, these greenhouse gases allow short-wave solar light to pass the

$\left.{ }^{*}\right)$ E-mail: Georg.erdmann@tu-berlin.de

$\left({ }^{* *}\right)$ E-mail: aaron.praktiknjo@rwth-aachen.de 
atmosphere while blocking the back-reflection of long-wave thermal radiation. Without this effect, the mean temperature of the globe would be $-18^{\circ} \mathrm{C}$ rather than $+16{ }^{\circ} \mathrm{C}$ at present. The actual debate on the GHG problem focuses on the concentration of $\mathrm{CO}_{2}$ in the atmosphere and on limiting its increase. Since the beginning of industrialization around 1840, it increased from 280 ppmv (parts per million by volume) to more than 410 ppmv as of 2020. The GHG effect of other emissions is expressed in $\mathrm{CO}_{2}$ equivalents: The $\mathrm{CO}_{2}$ equivalent of methane $\left(\mathrm{CH}_{4}\right)$ is 25 and of nitrous oxide $\left(\mathrm{N}_{2} \mathrm{O}\right) 298$ if a time horizon of 100 years is assumed $\left({ }^{1}\right)$. It is important to note that $\mathrm{CO}_{2}$ is no poison in the classic sense - it is even necessary for the growth of plants.

Annual global $\mathrm{CO}_{2}$ emissions stand at more than 35 billion tons (40 billion tons of $\mathrm{CO}_{2}$ equivalents from all GHG emissions). Since 2007 the GHG emissions have been slowly falling in Europe and remain stable in North America, but they are growing rapidly in the rest of the world, most notably in Asia in the wake of its strong economic growth. In the year 2020, the global mean temperature is already $1.1^{\circ} \mathrm{C}$ above the pre-industrial level. Without the abolishment of GHG emissions until the mid of this century, the mean global temperature is expected to increase by more than $3^{\circ} \mathrm{C}$ in the 21 st century which will probably cause dramatic consequences to the nature and to human civilizations: acidification of oceans, increased frequency of thunderstorms, changing distribution of precipitation, desertification, melting of glaciers, thawing of permafrost, a rising sea level, and changing habitats for plants and animals. However, some of the world's regions may also benefit from increased plant growth and reduced heating requirements due to higher temperatures. Since most of these regions are in the rich North while those negatively affected are in the poor South, the GHG problem raises major equity concerns (ref. [1], Chapt. 4).

From the viewpoint of economics, the reduction target should satisfy the condition for Pareto Optimality $\left({ }^{2}\right)$ : The present value of expected damages avoided thanks to the last reduction project is equal to the present value of the expected cost of avoiding them. This concept can be explained by fig. 1 (ref. [2], Chapt. 7.1).

For simplicity the analysis is limited to a company operating a plant and a neighbor in the plant's vicinity. Let emissions from the plant cause a loss of value to the neighbor. The situation can be characterized by the profit function of the company $\Pi=\Pi(E m)$ and the damage function of the neighbor $C_{\text {ext }}=C_{\text {ext }}(\mathrm{Em})$. Both are a function of emissions $E m$, which are assumed to vary in proportion with the production of the company. Accordingly, nothing is produced at the emissions level $E m=0$, but due to the fixed costs of the plant, the company is running a large loss (not explicitly shown in fig. 1). The profit maximum is achieved at $E m_{0}$, leading to a profit $\Pi_{0}$ and a damage to the neighbor $C_{\text {ext, } 0}$. If permitted to neglect the damages of the neighbor, the company chooses production and hence emissions accordingly. But this situation does not maximize social

$\left({ }^{1}\right)$ For a time horizon of 20 years, the $\mathrm{CO}_{2}$ equivalent of methane is 84 and thus much higher. $\left({ }^{2}\right)$ A situation is not Pareto optimal if it is possible to improve the situation of some economic agents without aggravating the situation of at least one other. Otherwise, the situation is called Pareto optimal. Note that Pareto optimality disregards distributional aspects that are often in the focus of political debates. 


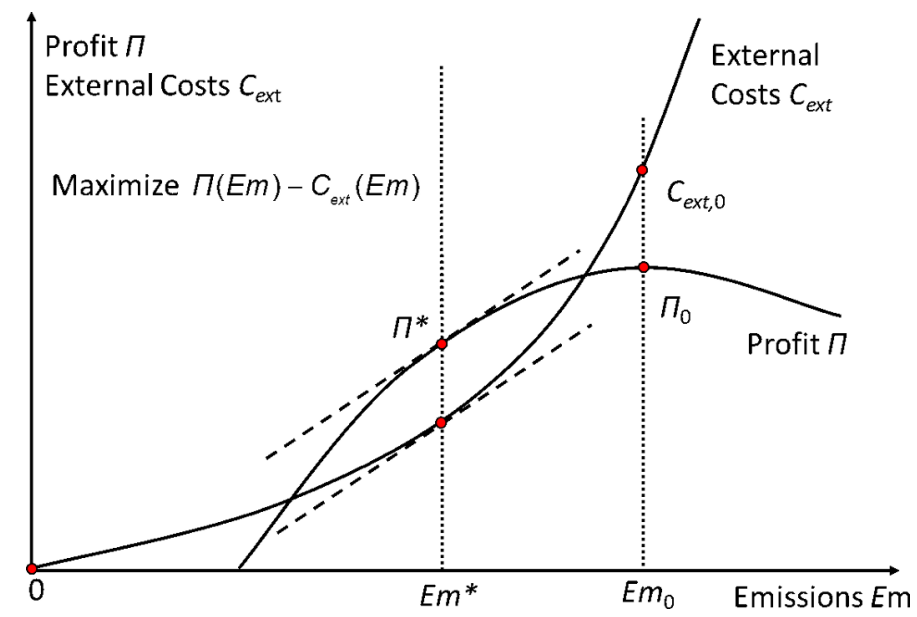

Fig. 1. - Optimal emission level.

welfare: If the plant were to decrease its production a bit, the loss in terms of profit would be less than the benefit in terms of damage avoided, the social welfare would increase. The social optimum is given at the emission level $E m^{*}$. In this situation the slope of the profit function equals the slope of the damage function, or in the scientific language, "marginal profit equals marginal damage". Since the marginal damage increases with emissions, $E m^{*}<E m_{0}$ holds, indicating that the social welfare maximizing amount of emissions is below the level that the company targets on its own. By the way, it does not make sense from an economic point of view to suppress production and emissions entirely, thus $E m^{*}>0\left({ }^{3}\right)$.

For translating this concept to the global GHG problem, the international community would need to calculate the expected damage associated with the GHG emissions of today and the expected costs of meeting a given reduced emission level. Unfortunately, due to the nature of the GHG problem both is virtually impossible. However, in 2015, a binding global GHG standard has been reached in international negotiations among governments and fixed in the Paris Agreement [3]: In the 21st century the global mean temperature increase should be limited to $2{ }^{\circ} \mathrm{C}$ at most, compared to pre-industrial level. Climatologists assume that this requires a sustainable $\mathrm{CO}_{2}$ concentration in the atmosphere below 450 ppmv.

Once the maximum $\mathrm{CO}_{2}$ concentration has been defined, appropriate emission trajectories $\left\{E m_{t}, t=1,2, \ldots\right\}$ are the result of a dynamic optimization problem based on

$$
M_{t}=M_{t-1}-\frac{1}{\tau}\left(M_{t-1}-M_{\text {pre }}\right)+\beta \cdot E m_{t} .
$$

$\left({ }^{3}\right)$ We will see that this condition is disputed in case of the global GHG problem. 
The concentration $M_{t}$ at time $t$ evolves from the previous year's concentration $M_{t-1}$ by subtracting the decay of inventory added to its pre-industrial level $M_{\text {pre }}$ and by adding a share $\beta$ of current emissions $E m_{t}$, which reflects that some part of annual emissions will not end up in the atmosphere but is sequestered by oceans and trees. In this equation, the parameter $\tau$ reflects the average duration of $\mathrm{CO}_{2}$ in the atmosphere $(\tau=120$ years according to the International Panel on Climate Change).

A large manifold of emission trajectories exist that would allow to limit the $\mathrm{CO}_{2}$ concentration in the atmosphere below the target value of $450 \mathrm{ppmv}$. Their common property is that annual reductions in future years need to be larger the later they begin.

Once a target emission trajectory is decided politically, the role of economists is to present solutions for implementing it in an economically most efficient way. This requires explicit or implicit price signals on $\mathrm{CO}_{2}$ and other GHG emissions. Basically, two alternatives are proposed: One is the introduction of a fiscal tax on GHG emissions, whereby the tax rate represents the explicit price of a GHG emission unit; it should evolve over time according to the targeted emission trajectory and vary accordingly. The other is the implementation of a mandatory cap-and-trade system for GHG emissions, whereby the regulator sets the annually available number of emission rights according to the targeted trajectory and distributes these emission allowances (mostly) through auctions, whereby the auction price depends on the supply and demand of emission rights and represents an implicit emission price.

\section{2. $-\mathrm{CO}_{2}$ tax systems}

To explain the economics of an emission tax system, we start with the assumption that the annual $\mathrm{CO}_{2}$ abatement cost curve of the country is known (see fig. 2). The abatement costs depend on the actual emissions, the available technological and institutional options to reduce these emissions, and certain aspects of the human behavior such as the propensity to waste energy. Due to the complexity of influencing factors, the abatement cost curve cannot be known with sufficient precision. In addition, it varies over time. Therefore, the above assumption is hypothetical, but it is used here to explain the mechanism of a $\mathrm{CO}_{2}$ tax.

Without reduction efforts, the annual abatement costs are zero. In fig. 2 this is highlighted as "starting point". When the society implements an emission reduction program, the economically optimal strategy is to start with measures that are relatively cheap in terms of cost per emission unit avoided. Once the cheap reduction potentials are exhausted, the reduction strategy should proceed to the next and more expensive measures and so forth. As a result, the aggregated abatement cost curve has a convex slope. It starts to the left from the starting point with cheap measures implying a small slope of the abatement curve, and proceeds to more expensive measures implying a steeper slope. It is important to note the implicit assumption in fig. 2 which requires decision makers faced with a $\mathrm{CO}_{2}$ tax not to tackle expensive reduction measures before cheaper measures have been initialized. 


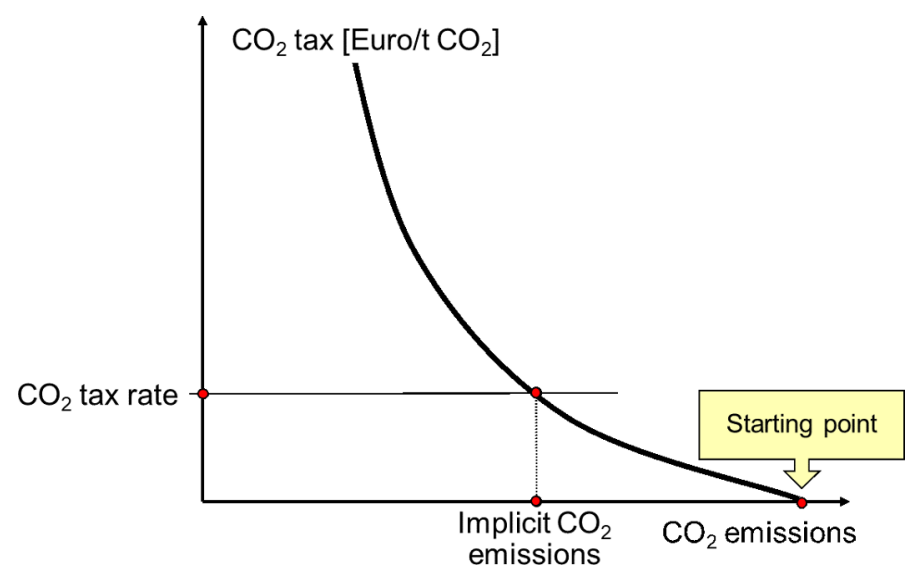

Fig. 2. $-\mathrm{CO}_{2}$ abatement cost and a $\mathrm{CO}_{2}$ tax system.

In fig. 2 the $\mathrm{CO}_{2}$ tax rate is represented by a horizontal line. The economically efficient reaction would be to realize all reduction measures with unit reduction costs below the defined $\mathrm{CO}_{2}$ tax rate and to pay the $\mathrm{CO}_{2}$ tax for the remaining emissions. Under these conditions, each $\mathrm{CO}_{2}$ tax rate is associated with implicit $\mathrm{CO}_{2}$ emissions which are below the starting point emissions such leading to emission reductions. According to fig. 2, the emission reduction increases with the tax rate so that the government can control the emission trajectory by defining a time path for the $\mathrm{CO}_{2}$ tax rate if it knows the slope of the aggregated abatement cost curve with sufficient precision.

The "beauty" of this approach is assumed to be the long-term stability and predictability of the $\mathrm{CO}_{2}$ tax rate, at least in principle. Thus, once a long-term emission trajectory is fixed, investors have calculable business incentives towards GHG abatement efforts. The tax system also creates a favorable environment for climate friendly innovations. But as explained above the knowledge about the abatement cost function is insufficient so that the $\mathrm{CO}_{2}$ tax rate may be too low compared to the target trajectory of $\mathrm{CO}_{2}$ emissions (if the true abatement costs are underestimated) or too high (if the true abatement costs are overestimated):

- Underestimation of the abatement costs is a typical consequence of investment decisions that are not efficient as assumed by the abatement cost curve. The excessive state aid in favor of relatively expensive clean electricity generation technologies can be taken as an example. It resulted in a quite expensive and economically inefficient GHG abatement measures. Other reasons such as the stickiness of producer and consumer behavior should also be mentioned here.

- On the other hand, the $\mathrm{CO}_{2}$ tax rate may be too high compared to the target trajectory of $\mathrm{CO}_{2}$ emissions. The most important reason is an unexpected success of clean innovations which reduces the future $\mathrm{CO}_{2}$ abatement costs. A corresponding success may allow more ambitious GHG reduction targets. But the GHG problem 
is not the only challenge to societies. As governments should take these into consideration, an excess $\mathrm{CO}_{2}$ tax rate is not recommendable $\left({ }^{4}\right)$.

Concluding, it is quite likely that governments will adjust their $\mathrm{CO}_{2}$ tax rate from time to time, so that a long-term stable and predictable $\mathrm{CO}_{2}$ tax system is unlikely. The "beauty" of the emission tax approach is therefore relative.

Typically, a tax system has the function to finance government expenditures. But a $\mathrm{CO}_{2}$ tax system may be faced with the problem that in the aftermath of the Paris Agreement 2015 many countries follow a "net-zero" GHG target. It means that in the second half of the current century the cumulated GHG emissions must be zero or fully compensated by taking the equivalent amount of greenhouse gases out of the atmosphere, for example by means of air cleaning, increased afforestation, or the burning of biomass in combination with carbon capture and storage. It is obvious that without $\mathrm{CO}_{2}$ emissions the revenue from any $\mathrm{CO}_{2}$ tax is zero. If technologies with negative GHG emissions are applied, an effective $\mathrm{CO}_{2}$ tax system would require tax credits according to their net effect on the greenhouse gas inventory.

The implication is that in a "net zero" world the $\mathrm{CO}_{2}$ tax credits would equalize the $\mathrm{CO}_{2}$ taxes so that in the long run the $\mathrm{CO}_{2}$ taxes will not generate revenues to the governments. For this reason, it would be wise not to use $\mathrm{CO}_{2}$ tax revenues for general government spending but rather for supporting GHG reduction projects financially. Once "net zero" is reached, these projects become obsolete and need no more public support. Alternatively, governments could utilize $\mathrm{CO}_{2}$ tax revenues for equal per-capita transfers to its citizens as is presently the case in Switzerland.

\section{3. - $\mathrm{CO}_{2}$ cap-and-trade systems}

While a $\mathrm{CO}_{2}$ tax system solves the economic concept of putting a direct price signal on $\mathrm{CO}_{2}$ emissions, the cap-and-trade system generates an indirect price signal. It starts by defining an aggregate cap on annual $\mathrm{CO}_{2}$ emissions whereby this cap decreases over time according to the target emission trajectory. Governments define and distribute the emission rights according to the annual cap. One emission right gives the right to emit one ton of $\mathrm{CO}_{2}$, or the equivalent amount of the greenhouse gases nitrous oxide (N2O) and perfluorocarbons (PFCs). The typical distribution channel is through auctions; thus, companies have to pay for the emission rights. Some emission rights may also be distributed for free, for example to the operators of CHP stations (Combined Heat and Power) or to companies that otherwise may not be competitive on international markets.

Governments have also to determine which legal entities should be obliged to take part in the cap-and-trade system. Typically, only large emitters are required to participate. In the European emission trade system [5], electricity generation units (> 20 MW), and

$\left({ }^{4}\right)$ Here a discussion of carbon leakage would be necessary. Carbon leakage means that production processes with high $\mathrm{CO}_{2}$ emissions may be relocated to countries with lower or zero $\mathrm{CO}_{2}$ tax rates. In this case a raising $\mathrm{CO}_{2}$ tax in one country would not reduce $\mathrm{CO}_{2}$ emissions on the global level. See [4]. 

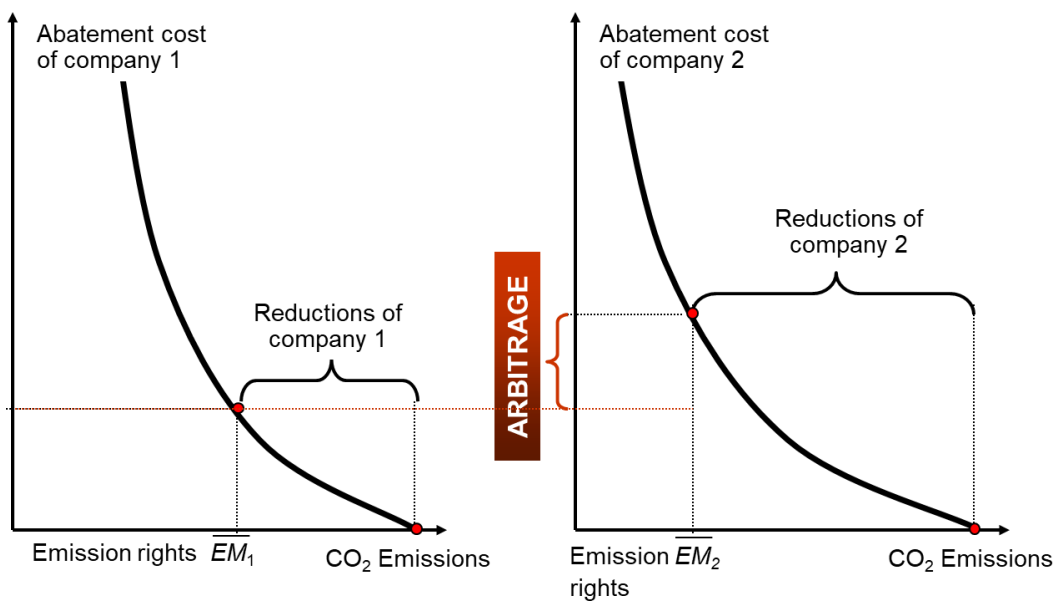

Fig. 3. - Benefit of emission trading.

companies from iron and steel, glass, paper, cement and chemical industry are obliged, but not other industry sectors. In the first quarter of each year, each obligated company has to submit the appropriate number of emission rights (emission allowances) according to the company's $\mathrm{CO}_{2}$ emissions of the previous year. The companies have to confirm the annual emissions by a verified emission report, similar to an annual tax declaration and then to deliver the appropriate number of emission rights to the government.

The introduction of a cap-and-trade system requires the imposition of sanctions on obligated companies that fail to submit the required number of emission rights. In the case of the EU-ETS the penalty stands presently at 100 Euro/ton $\mathrm{CO}_{2}$ [5] and has to be paid by companies which delver an insufficient number of emission rights at the end of the trading period (presently 2013-2020 and then from 2021-2030). In addition, the misbehaving company has to deliver the equivalent number of emission rights of the next trading period. Thus, the maximum effective $\mathrm{CO}_{2}$ penalty could largely exceed the 100 Euro/ton $\mathrm{CO}_{2}\left({ }^{5}\right)$.

A central element of a cap-and-trade system is the tradability of $\mathrm{CO}_{2}$ emission rights on emission markets. This allows the market to identify the cheapest technology mix for a given cap or GHG reduction target. This is explained in fig. 3 with two companies causing individual emissions prior to the allocation of emission rights. Each company is faced with a company specific abatement cost curve. The abatement cost curves are convex, similar to fig. 2. The abatement cost schedules usually differ between companies. In fig. 3, company 2 faces more quickly increasing costs than does company 1.

Figure 3 assumes that the two companies have obtained emission rights $E m_{1}$ and $E m_{2}$, which forces them to individually reduce their emissions, starting of course with

$\left({ }^{5}\right)$ Within a trading period, a shortfall of emission rights can be compensated by emission rights pertaining to the following year, whereas an excess of rights can be used not only within the present trading period but also during the next trading period. 
the least costly measures. In the example shown in fig. 3, company 2 incurs much higher unit abatement cost for reaching its emission cap than company 1 .

For company 2, it would make economic sense to buy extra emission rights from company 1 which would prevent it from investing into expensive abatement projects. Company 2 would be prepared to pay the unit cost avoided for the emission right. If company 1 would sell the corresponding number of emission rights, it needs to reduce its emissions beyond $E m_{1}$, but benefits from the trade as its individual unit abatement costs are below the price for the emission rights paid by company 2. Company 2 also benefits as the price for the emission rights is below the cost of abatement projects that it can avoid.

Thus, the difference in the abatement cost at the respective values $E m_{1}$ and $E m_{2}$ creates room for arbitrage trading which is profitable for both companies. The arbitrage implies that company 1 reduces emissions beyond $E m_{1}$, in return receiving revenue from selling the corresponding emission rights to company 2. On the other hand, company 2 purchases emission rights as long as they are cheaper than its unit abatement cost. In the optimum, arbitrage is eliminated through trade, resulting in equality of unit abatement cost for both companies $\left({ }^{6}\right)$.

The flexibility of the cap-and-trade system should in principle reduce the costs of achieving ambitious emission targets compared to an equivalent emission tax system. However, this aspect has not received much attention in the scientific discussion. On the other hand, the shortcomings of a cap-and-trade system, the typically low and rather volatile price of the emission rights, has received much attention among scientists and politicians.

An example is the development of the EU-ETS price on the European spot market shown in fig. 4. At the beginning of the trading period 2008-2012 the EUA price reached 30 Euro/t $\mathrm{CO}_{2}$. It then dropped sharply and went down to 5 Euro/t at the beginning of the trading period 2013-2020. This caused a political reform of the EU-ETS through which a market stability reserve was introduced which should stabilize the EU-ETS price. In addition, some emission rights have been permanently taken out of the system which caused the EU-ETS price to increase to $>25$ Euro/t in January 2018. The price drop in April 2020 was the consequence of the economic lockdown in many European states during the Corona crisis.

As a result of volatile prices of emission rights, governments will not receive stable revenues if they distribute the emission rights through auctions. As seen above, this aspect is not basically different to a $\mathrm{CO}_{2}$ tax system, but in the case of a cap-and-trade system more urgent. Again, governments should use the revenues from auctioning $\mathrm{CO}_{2}$ emission rights for sponsoring GHG reduction projects or by equal per-capita transfers to its citizens.

$\left({ }^{6}\right)$ Speculative trade may influence the markets for emission rights, depending on the expectations of market participants. If an increase in the price of certificates is expected, speculators go along (i.e. purchase rights in excess of marginal abatement cost) and vice versa. If their expectations turn out to be right, speculators make a profit, otherwise they suffer a loss. 


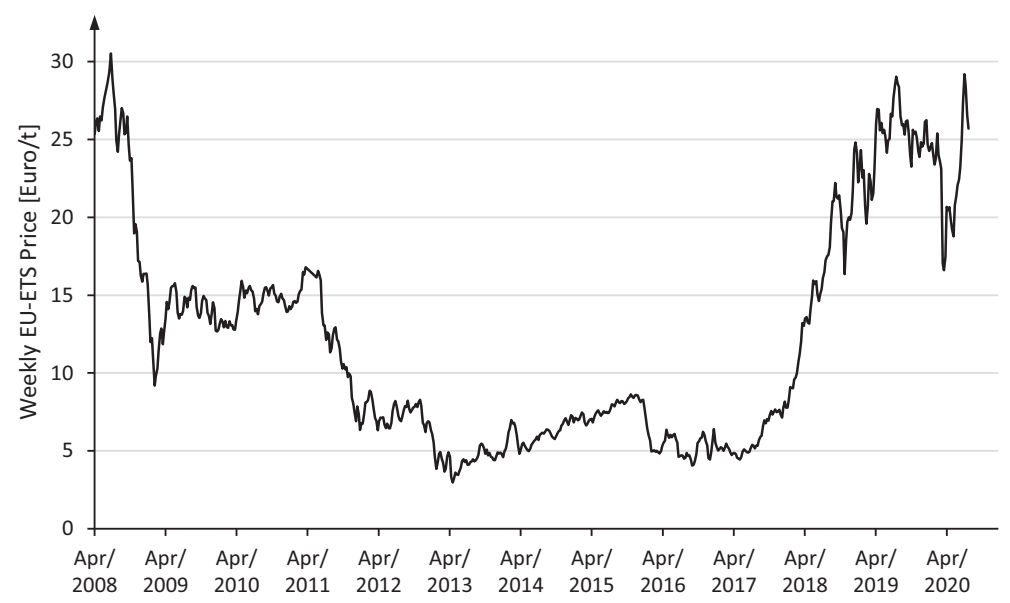

Fig. 4. - Weekly EU-ETS Price since 2008 (Data source: [6]).

\section{4. - Comparison and analysis}

The $\mathrm{CO}_{2}$ prices in countries who had implemented an emission tax systems are typically higher and more stable than the implicit $\mathrm{CO}_{2}$ price of a cap-and-trade system. According to data from the World Bank [7], high carbon taxes are implemented until 2018 in Finland (62 Euro/t), France (44.40 Euro/t), Norway (51 Euro/t), Sweden (124 Euro/t), Switzerland (84 Euro/t) $\left({ }^{7}\right)$ and UK (20 Euro/t top of the EU-ETS price). Such taxes should establish strong incentives towards private investments into GHG abatement technologies. From a theoretical point of view, this is not to be expected under a cap-and-trade system with its volatile and rather low prices for $\mathrm{CO}_{2}$ emission rights so that the EU-ETS could fail. But in reality the situation is quite different. In 2018 the European Union has achieved a 23\% GHG reduction compared to 1990 and thus will surpass its emission target for 2020 (even without the recession caused by the Corona pandemic [9]). As the EU-ETS is regarded as the cornerstone of the European policy to combat climate change, covering $50 \%$ of the Union's GHG emissions, the negative judgement of the European cap-and-trade systems must be revised.

But what could be the reasons for the surprising success of supposedly inappropriate cap-and-trade systems? According to the standard approach of economics, the impact of the $\mathrm{CO}_{2}$ price should be symmetric, as suggested by fig. 5. It shows the aggregate emission reduction curve representing the technological and institutional options that are available in a certain year. The $\mathrm{CO}_{2}$ tax rate would explicitly define the $\mathrm{CO}_{2}$ price and

$\left({ }^{7}\right)$ In spite of its rather high $\mathrm{CO}_{2}$ tax rate and the economic recession of 2020 caused by the Corona crisis, Switzerland will not meet its GHG emission goal for 2020, which requires a $20 \%$ reduction compared to 1990 . In 2018 the GHG missions of the country dropped by only $13.6 \%$ against 1990, see [8]. 


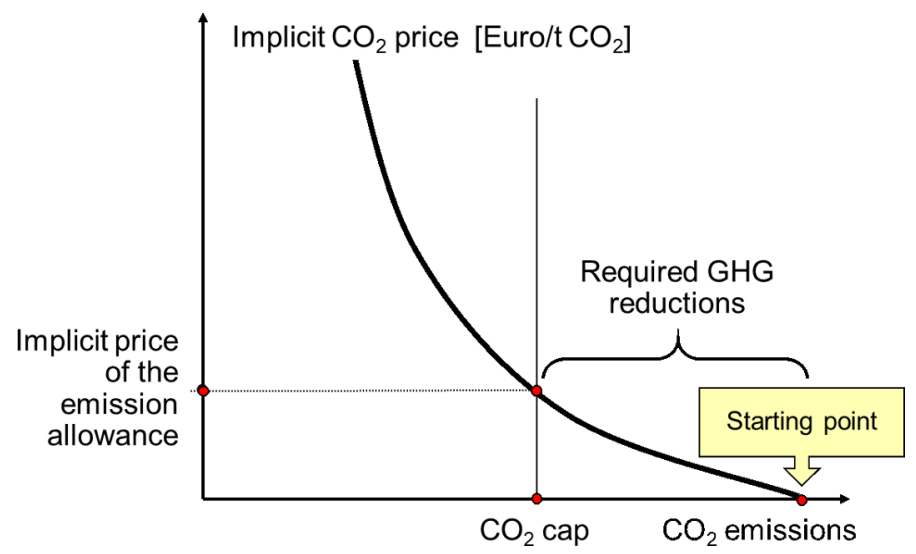

Fig. 5. $-\mathrm{CO}_{2}$ abatement costs in a cap-and-trade system.

implicitly define the associated $\mathrm{CO}_{2}$ reductions, while the $\mathrm{CO}_{2}$ cap explicitly defines the $\mathrm{CO}_{2}$ reductions and implicitly the $\mathrm{CO}_{2}$ price.

This symmetry is broken once the government or regulator do not know the shape of the expected emission reduction curve with sufficient precision. Expectation errors have different implications: Under a $\mathrm{CO}_{2}$ tax system, the emission reduction targets may be missed, while the tax revenues to the governments are stable. Under a $\mathrm{CO}_{2}$ cap-andtrade system, the emission reduction targets are reached while the implicit $\mathrm{CO}_{2}$ price and thus the revenues to the government are instable. The assessment of this difference depends on whether the evaluation is taking the standpoint of the finance minister or the minister of environment.

There are more aspects when comparing the two systems. Above, it was discussed that the selection of emission reduction projects would be more efficient under a $\mathrm{CO}_{2}$ cap-and-trade system than under a $\mathrm{CO}_{2}$ tax system. Therefore, an implicit $\mathrm{CO}_{2}$ price resulting from a cap-and-trade system would have a stronger effect on reducing GHG emissions than an equal $\mathrm{CO}_{2}$ tax rate.

The second, and to my view more important, aspect is the explicit penalty to noncomplying companies that is a necessary element in any cap-and-trade system. If companies do not present a sufficient number of emission rights at the end of each trading period (2012-2020 and 2021-2030), the fine is equal to the number of missing emission rights times the penalty of 100 Euro. For companies that refuse to reduce emissions and to purchase the necessary number of emission rights, the penalty is somehow equivalent to a $\mathrm{CO}_{2}$ tax, with the exception, that non-complying companies have to purchase emission rights of the next trading period and to deliver them to the regulator. Thus, the "true penalty" exceeds the 100 Euro/t by the market price of the emission right.

It seems that the price signal of a cap-and-trade system is not (only) defined by the volatile short-term market price of emission rights, but rather the "true penalty" as defined above. Regarding the length of trading periods, companies have sufficient time 
to plan their strategies and abatement measures, independent from the actual price of the $\mathrm{CO}_{2}$ emission right, as their motivation is to avoid penalty payments of an eventually high and unknown magnitude at the end of the trading period.

But why companies do not purchase emission rights during periods with low $\mathrm{CO}_{2}$ prices, in excess of their expected demand? From a mere economic point of view, this would be optimal instead of investing into expensive $\mathrm{CO}_{2}$ abatement technologies. But companies may expect national governments and the EU Commission to tighten their GHG policy in the future so that a strategy based on short-term $\mathrm{CO}_{2}$ prices is not the preferred strategy. This expectation is not unrealistic, regarding the many political decisions of the European Union in recent years that modified the EU-ETS system in the interest of higher and more stable prices for the emission rights (see $[9])\left({ }^{8}\right)$.

\section{5. - Outlook}

Regarding the two-degree celsius target of the Paris Agreement 2015, governments have to put additional efforts and instruments into force in order to reach the corresponding GHG emission goals. It is also quite likely that pricing of GHG emissions will play a larger role in the future, even if this idea is not mentioned in the Paris Agreement of 2015 [3]. The present paper should have made clear that it is not possible to control both the emission price and the emission volume at the same time. Thus, governments will have to choose between GHG tax systems and GHG or cap-and-trade systems. Both systems have their benefits and disadvantages and thus a complex choice has to be taken.

Also, hybrid solutions may apply: The energy intensive industries may be forced to take part in a cap-and-trade system, while the GHG emissions from the transportation and heating sectors are controlled by emission taxes.

In the first instance, the basic benefit of tax systems consists in a relative stable flow of income to the governments in the next years, while the basic benefit of a cap-andtrade system is the likely achievement of the emission targets. But due to the lack of central knowledge about the expected emission reduction options including their costs, tax systems have to be adjusted from time to time in order to meet the emission targets. On the other hand, cap-and-trade systems are also adjusted from time to time in order to generate higher revenues to the government, even if their success on reducing the GHG emission has been proven. Perhaps this is due to the influence of green lobby groups that claim for high and stable financial support from the government according to their interests and require governments to acquire the corresponding revenues.

$\left.{ }^{8}\right)$ As a consequence, the available number of European emission rights will not be fully independent of the price of the emission right, which would be the case in a strict cap-and-trade system. In the future, EU-ETS may become a mix of a mere tax system and a mere cap-andtrade system. 


\section{REFERENCES}

[1] Bretschger L., Green Economy, Graying Society (CER-ETH Press, Zürich) 2015.

[2] Zweifel P., Praktiknjo A. and Erdmann G., Energy Economics. Theory and Applications (Springer, Berlin) 2017.

[3] United Nations (2015) Paris Agreement, Conference of the parties to the UNFCCC, adopted in Paris, 12 December 2015.

[4] Kaufmann C. and Weber R. H., "Carbon-related border tax adjustment: mitigating climate change or restricting international trade", World Trade Rev., 10 (2011) 497.

[5] Directive 2003/87/EC of the European Parliament and of the Council of 13 October 2003 establishing a scheme for greenhouse gas emission allowance trading within the Community and amending Council Directive 96/61/EC (EU Commission, Brussels) 2003.

[6] Sandbag Climate Campaign CIC (EUA Price, London) 2020, https:// ember-climate.org/carbon-price-viewer.

[7] Carbon Pricing Dashboard (The World Bank, Washington D.C.) 2020, https:// carbonpricingdashboard. worldbank.org/map_data.

[8] Emissionen von Treibhausgasen nach revidiertem $\mathrm{CO}_{2}$-Gesetz und KyotoProtokoll (Bundesamt für Umwelt (Bafu), Bern) 2020, www.bafu.admin.ch/dam/ bafu/de/dokumente/klima/fachinfo-daten/C02_Statistik.pdf .download.pdf/CO2_ Publikation_de_2020-07.pdf.

[9] EU Emissions Trading System (EU ETS) (European Commission, Brussels) 2020, https://ec.europa.eu/clima/policies/ets_en. 